\title{
Courseware Reviews
}

\section{A Printed Version of the Web Site}

\section{Strengths}

of the Book and the Web Site
Internet Resources is a printed version of the web site "Online Resources and Journals: ELT, Linguistics, and Communication" (http://ilc2.doshisha.ac.jp/users/kkitao/ online/). It is the author's intention to present in book format a wide variety of language resources that he has linked to or developed on his web site so that readers of this book can obtain more benefit with less effort. The book is separated into two parts: "Part One: Online Resources" and "Part Two: Archives" with Part One subdivided into four sections: "Introduction," "Using the Internet," "Useful Mailing Lists," and "Useful WWW Sites," The book is then further divided into fifty-five chapters, which fall into two introductory and resource listing categories. The introductory chapters give brief accounts on what the Internet and various Internet applications such as email, mailing lists, WWW, Telnet, FTP, etc. are and how to use these resources effectively. The resource listing chapters, which constitute the main body of the book, provide various mailing lists such as LINGUIST and TESL-L, web sites, and archives for related groups of academic readers. The mailing list chapters also offer detailed instructions on how to subscribe to individual mailing lists and how to retrieve and obtain information from these mailing lists.

The Internet resources compiled in the book have been accumulated and posted on the web site for more than two years. Targeted mainly at graduate students, teachers, and researchers, the book clearly explains the advantages and disadvantages of using various Internet applications and Internet resources for language disciplines. Relevant Internet resources are carefully selected, classified, and annotated. Interesting topics that go beyond introductory explanations include "Professional Development for English Language Teachers," "Using the Internet for Teaching English," "Academic Publication and the Internet," and "Student Lists," Interested users will find useful Internet resources on associations, conferences, institutions, newsletters, publishers, software developers, bookstores, and other reference materials for TEFL/TESL, linguistics, and communication. The book includes also reference materials such as papers, articles, bibliographies, and re- 
Differences Between Book and Web Site

"This book will be a practical, useful reference work for users of the related Web site and interested students and researchers in ELT, linguistics and communication." ports, style sheets, dictionaries, thesauruses, quotations, encyclopedias, grammar, writing, job listings, lesson plans, tests, email keypal opportunities, literature, and more.

A comparison of the book with the web site reveals interesting differences between the book and the original web site. The book has lost the point-and-click hypertext functionality of the web site, and is therefore not truly a gateway to bountiful Internet resources but rather a reference work on these resources. In addition, the print version does not contain resources in Japanese and journals, as the web site does. It has, however, gained in readability over the online version through an improved and systematic organization of the materials from the web site. The more systematic organization of materials is a substantial plus to the reader who is seeking more than a general overview of Internet resources and who has the time to read these explanatory materials in more detail. The print table of contents gives a good overview of the contents of the book and helps the users who get lost in the labyrinth of the Internet back on the track of purposeful use of Internet resources. In this sense, this book can serve as an instruction manual to accompany the web site. Certainly it also can be used off-line," especially if the users want to better understand various concepts and uses of the Internet and its various applications.

Despite the improvements in the structure of the book compared with that of the web site, the book too would benefit from a more balanced organization. The second half of the book is, for example, too short. A more even balance between the two parts would be a solution. One the other hand, the book lacks a useful index. Adding indexes will help the readers more effectively find information they need and thus substantially increase the value of the book (This is equally true of the web site: A web site-bound search engine will assist the users in finding information available and prevent them from getting lost in the information jungle of the site).

This book will be a practical, useful reference work for users of the related web site and interested students and researchers in ELT, linguistics and communication. It is meaningfully structured, well explained, and easy to use. Due to the dynamic nature of the WWW, the book needs, however, a more distinct organizational structure and index, as well as updates and further improvements on a regular basis.

Peter Yang is Jesse Hauk Shera Assistant Professor of German, Chinese and Comparative Literature and the Director of the Language Resource Center at Case Western Reserve University. 